\title{
PET/CT and MRI in Bladder Cancer
}

\author{
Kirsten Bouchelouche ${ }^{1 *}$, Baris Turkbey ${ }^{2}$ and Peter L Choyke ${ }^{2}$
}

${ }^{1}$ Department of Nuclear Medicine \& PET Centre, Aarhus University Hospital, Skejby, Denmark

${ }^{2}$ Molecular Imaging Program, National Cancer Institute (NCI), National Institutes of Health (NIH), Bethesda, MD, USA

\begin{abstract}
Bladder Cancer ( $\mathrm{BCa}$ ) is the most common malignancy arising from the urinary tract. One of the mainstays of diagnosis, staging, and therapeutic decision-making for $\mathrm{BCa}$ is accurate and appropriate imaging. The ability to identify metastatic disease preoperatively is of utmost importance in determining treatment. Advances in standard cross sectional imaging techniques like Computed Tomography (CT) and Magnetic Resonance Imaging (MRI) have improved imaging of bladder cancer. Over the last decade, ${ }^{18} \mathrm{~F}$-fluorodeoxyglucose (FDG) Positron Emission Tomography (PET) in combination with CT ( ${ }^{18} \mathrm{~F}-\mathrm{FDG}$ PET/CT) has become an important non-invasive imaging modality for the preoperative staging of various malignancies. ${ }^{18} \mathrm{~F}-\mathrm{FDG}$ PET/CT is useful for detection of metastatic disease in $\mathrm{BCa}$, but the ability to detect primary bladder wall lesions remains to be elucidated. To overcome the problem with urinary excretion of ${ }^{18} \mathrm{~F}-\mathrm{FDG}$, new PET tracers are being tested. MRI is an accurate technique for the local staging of $\mathrm{BCa}$ due to its superior spatial and contrast resolution. Anatomical MRI has a modest utility in NMstaging of $\mathrm{BCa}$. However, incorporation of functional MR techniques, such as diffusion weighted MRI can improve the results for lesion detection and staging and multi-parametric MRI's role is yet to be explored widely. The aim of this review is to present the recent advances in PET/CT and MRI in BCa, with particular focus on improvements in staging.
\end{abstract}

Keywords: Positron Emission Tomography/Computed Tomography (PET/CT); Magnetic Resonance Imaging (MRI); Urothelial cancer; Bladder cancer

\section{Introduction}

Bladder Cancer (BCa) is a heterogeneous disease, with $70 \%$ of patients presenting with superficial tumours, which tend to recur but are generally not life threatening, and $30 \%$ presenting as muscle-invasive disease associated with a high risk of death from distant metastases [1]. More than $90 \%$ of $\mathrm{BCa}$ are transitional cell carcinomas, $5 \%$ are squamous cell carcinomas, and less than $2 \%$ are adenocarcinomas [1]. Most often BCa present with painless haematuria, and the standard method of diagnosing BCa continues to be based on direct visualization of the bladder with cystoscopy including biopsy/resection with histological examination of the tissue. The risk of metastases is very low when the disease is superficial. Therapy for superficial tumours is complete endoscopic resection with or without additional intravesical chemotherapy. The standard treatment of muscle invasive $\mathrm{BCa}$ is radical cystoprostatectomy for men and anterior exenterationincluding the bladder, urethra, uterus, and ventral vaginal wallfor women [1]. Pelvic lymphadenectomy is performed routinely in all cases of radical cystectomy. Although radical cystectomy is the preferred treatment for muscle invasive disease, metastases develop in about $25 \%$ of cases with tumours invading the muscular layer only and in about $50 \%$ with tumours extending into the perivesical tissue [2]. Neoadjuvant and adjuvant chemotherapy have been used in an attempt to improve outcomes for patients with high-risk muscle invasive disease, and systematic chemotherapy using multidrug regimens is the standard therapy for metastatic disease. Accurate staging is pivotal in optimal therapy planning and in avoiding radical surgery in incurable patients. The aim of this review is to present the recent advances in Positron Emission Tomography/Computed Tomography (PET/ $\mathrm{CT}$ ) and Magnetic Resonance Imaging (MRI) imaging of $\mathrm{BCa}$, with particular focus on improvements in staging.

\section{$\mathrm{PET} / \mathrm{CT}$}

For many years PET/CT with ${ }^{18} \mathrm{~F}$-fluorodeoxyglucose $\left({ }^{18} \mathrm{~F}-\mathrm{FDG}\right)$ has been an important non-invasive imaging modality for the preoperative staging of various neoplasms. ${ }^{18} \mathrm{~F}-\mathrm{FDG}$ is a marker of increased glucose uptake. Many malignant neoplasm and their metastases are characterized by enhanced glucose utilisation and therefore increased glucose uptake. As an analog of glucose, ${ }^{18} \mathrm{~F}-\mathrm{FDG}$ is taken up within tumor cells via GLUT and other transporters where it is phosphorylated by hexokinase but not further metabolized, leading to intracellular accumulation. PET imaging in combination with CT offers a high sensitivity scan for metabolic activity with precise anatomical localization. There has been a limited number of reports on the utilization of ${ }^{18} \mathrm{~F}-\mathrm{FDG}$ PET/CT to image $\mathrm{BCa}$, mainly because the urinary excretion of ${ }^{18} \mathrm{~F}-\mathrm{FDG}$ interferes with the ability to distinguish wall activity from luminal activity [3]. Therefore, other tracers like ${ }^{11} \mathrm{C}$-choline, ${ }^{11} \mathrm{C}$-acetate, and ${ }^{11} \mathrm{C}$-methionine, all of which have minimal urinary excretion, have been used for PET/CT in BCa.

The pooled activity of urinary excreted ${ }^{18} \mathrm{~F}-\mathrm{FDG}$ in the urinary bladder makes the evaluation of primary bladder wall lesions difficult or even impossible (Figure 1). Adequate pre-hydration is important to ensure a sufficiently low ${ }^{18} \mathrm{~F}$-FDG concentration of ${ }^{18} \mathrm{~F}$-FDG in urine (less artefacts) and for radiation safety reasons (for example, 1/2-1 $\mathrm{l}$ of water in the $1-2 \mathrm{~h}$ prior to injection). Emptying the bladder just before the PET/CT will also reduce urinary excreted ${ }^{18} \mathrm{~F}-\mathrm{FDG}$ in the bladder. Interventions such as adequate hydration, bladder irrigation and drainage, forced diuresis with furosemide, or both, have been used in order of overcoming the problem with urinary excreted ${ }^{18} \mathrm{~F}-\mathrm{FDG}$

*Corresponding author: Kirsten Bouchelouche, MD, DMSc, Chief Physician Department of Nuclear Medicine \& PET Centre, Aarhus University Hospital, Skejby Brendstrupgaardsvej 100, DK-8200 Aarhus, Denmark, E-mail: kirsbouc@rm.dk

Received June 07, 2012; Accepted July 28 2012; Published July 30, 2012

Citation: Bouchelouche K, Turkbey B, Choyke PL (2012) PET/CT and MRI in Bladder Cancer. J Cancer Sci Ther S14:001. doi:10.4172/1948-5956.S14-001

Copyright: (c) 2012 Bouchelouche K, et al. This is an open-access article distributed under the terms of the Creative Commons Attribution License, which permits unrestricted use, distribution, and reproduction in any medium, provided the original author and source are credited. 
in the bladder [4-8]. Anjos et al. [4] performed ${ }^{18} \mathrm{~F}-\mathrm{FDG}$ PET/CT in 11 patients with muscle invasive $\mathrm{BCa}$ and demonstrated a sensitivity of $54 \%$ for detection of malignant areas in the bladder wall. Recently, Harkirat et al. [5] demonstrated a sensitivity and specificity of $86.7 \%$ and $100 \%$ respectively, for detection of primary bladder lesions in 22 patients with invasive BCa. Delayed pelvic images after diuretic administration and oral hydration were used in both studies $[4,5]$. Recently, Lodde et al. [6] performed ${ }^{18} \mathrm{~F}-\mathrm{FDG}$ PET/CT and forced diuresis in 44 patients with known muscle invasive $\mathrm{BCa}$ and compared the findings with standard CT. They demonstrated that ${ }^{18} \mathrm{~F}-\mathrm{FDG}$ PET/ CT was more sensitive ( $85 \%$ vs. $77 \%$ ) but less specific ( $25 \%$ vs. $50 \%$ ) than $\mathrm{CT}$ alone for detecting primary tumours.

Accurate detection of metastases in $\mathrm{BCa}$ is an essential component of the decision making for appropriate treatment. Metastases are rarely associated with superficial disease. However, for muscle-invasive $\mathrm{BCa}$, additional imaging workup procedures are needed for accurate staging. In this setting bladder activity is much less of a problem. Yet only a few reports on the preoperative staging of BCa with ${ }^{18}$ F-FDG can be found in the literature [6,9-13]. Drieskens et al. [11] investigated the value of pre-operative ${ }^{18} \mathrm{~F}-\mathrm{FDG} \mathrm{PET} / \mathrm{CT}$ in detecting metastatic disease in 55 patients with BCa. Correlative imaging of PET and CT was performed. The gold standard (histology) was available in only 40 patients. For the diagnosis of NM-positive disease, the sensitivity, specificity, and accuracy of ${ }^{18} \mathrm{~F}$-FDG PET (CT) were $60 \%, 88 \%$, and $78 \%$, respectively. Swinnen et al. [12] investigated the role of ${ }^{18} \mathrm{~F}-\mathrm{FDG}$ PET/ $\mathrm{CT}$ for $\mathrm{N}$-staging of BCa. Fifty-one patients underwent a pre-operative ${ }^{18} \mathrm{~F}^{-} \mathrm{FDG}$ PET/CT. All patients underwent a radical cystectomy and an extended lymphadenectomy. The ${ }^{18} \mathrm{~F}-\mathrm{FDG}$ PET/CT results were compared with the definitive pathologic results. For the diagnosis of node-positive disease, the sensitivity, the specificity, and the accuracy of ${ }^{18} \mathrm{~F}-\mathrm{FDG}-\mathrm{PET} / \mathrm{CT}$ were $46 \%, 97 \%$, and $84 \%$, respectively. When analysing the results of CT alone, there was a sensitivity of $46 \%$, specificity of $92 \%$ and an accuracy of $80 \%$. No real, statistically significant difference between CT and ${ }^{18} \mathrm{~F}-\mathrm{FDG}$ PET/CT was found. In contrast, Lodde et al. [6] reported that for the detection of pelvic node metastasis ${ }^{18} \mathrm{~F}$-FDG-PET/CT was more sensitive than CT (57\% vs $33 \%$ ) with a specificity and PPV of $100 \%$ for both imaging techniques. Thus, the study demonstrated superiority of ${ }^{18} \mathrm{~F}$-FDG PET/CT over standard CT for detecting lymph node metastasis (Figure 2).

Recently, Kibel et al. [14] reported a prospective study with ${ }^{18} \mathrm{~F}-\mathrm{FDG}$ $\mathrm{PET} / \mathrm{CT}$ in 43 patients undergoing radical cystectomy for cT2-3N0M0 urothelial carcinoma of the bladder. All had negative conventional $\mathrm{CT}$ and bone scan before enrolment. ${ }^{18} \mathrm{~F}-\mathrm{FDG}$ PET/CT finding were confirmed by percutaneous biopsy or by open surgical exploration, whereas negative ${ }^{18} \mathrm{~F}-\mathrm{FDG}$ PET/CT findings were confirmed by complete lymphadenectomy. ${ }^{18} \mathrm{~F}-\mathrm{FDG}$ PET/CT demonstrated a positive predictive value of $78 \%$ (7/9), a negative predictive value of $91 \%$ (30/33), sensitivity of $70 \%$ (7/10), and specificity of $94 \%(30 / 32)$. PET findings correlated significantly with recurrence-free survival ( $0 \%$ at 24 months in PET positive cases vs.55\% in PET negative cases), disease specific survival ( $23 \%$ vs. $62 \%$, respectively, at 24 months) and overall survival ( $23 \%$ vs. $58 \%$, respectively, at 24 months). The authors concluded that ${ }^{18} \mathrm{~F}-\mathrm{FDG}$ PET/CT may play an important role in planning treatment strategies prior to cystectomy. Jensen et al. [10] compared ${ }^{18} \mathrm{~F}$-FDG PET/CT and MRI for preoperative $\mathrm{N}$-staging in 18 patients with BCa. Histology was used as the gold standard. No statistically significant difference was found between ${ }^{18} \mathrm{~F}-\mathrm{FDG}$ PET/ $\mathrm{CT}$ and MRI for N-staging. However, there was a trend toward higher specificity for ${ }^{18} \mathrm{~F}-\mathrm{FDG}$ PET/CT vs. MRI (93\% vs. $\left.80 \%\right)$ as well as a higher NPV ( $87.5 \%$ vs. $80 \%$ ), but the difference did not reach statistical significance. The results were likely limited by the relatively small patient population. Recently, at MSKCC, Apolo et al. [15] evaluated the role of ${ }^{18} \mathrm{~F}-\mathrm{FDG}$ PET/CT for detection of metastatic disease in advanced $\mathrm{BCa}$. One hundred thirty-five individual lesions were evaluable in 47 patients for the organ-based analysis. Overall sensitivity and specificity were $87 \%$ (95\% CI, $76 \%$ to $94 \%$ ) and $88 \%$ (95\% CI, $78 \%$ to $95 \%)$, respectively. In the patient-based analysis, malignant disease was correctly diagnosed in 25 of 31 patients, resulting in a sensitivity of $81 \%$ (95\% CI, 63\% to $93 \%$ ). ${ }^{18} \mathrm{~F}$-FDG-PET/CT detected more malignant disease than conventional CT/MRI in $40 \%$ of patients. Furthermore, clinicians changed their planned management in $68 \%$ of patients based on the ${ }^{18} \mathrm{~F}$-FDG-PET/CT results. The authors concluded that ${ }^{18} \mathrm{~F}-\mathrm{FDG}-$ PET/CT has excellent sensitivity and specificity in the detection of metastatic BCa and provides additional diagnostic information that enhances clinical management more than CT/MRI alone.

The overall prognosis for recurrent and metastatic bladder TCC is poor. However, additional salvage and/or palliative therapies are prompted when disease is discovered. Accurate restaging is therefore important before additional costly and toxic therapies are considered. There are few data available regarding the utility of ${ }^{18} \mathrm{~F}-\mathrm{FDG}$ PET or ${ }^{18} \mathrm{~F}-\mathrm{FDG}$ PET/CT in assessing for recurrence and metastatic disease in patients who have previously undergone treatment for their primary $\mathrm{BCa}[4-6,16]$. Detection of locally recurrent or residual bladder tumours may also be improved using ${ }^{18} \mathrm{~F}$-FDG PET/CT with delayed images after a diuretic and oral hydration [4-6]. Jadvar et al. [16] retrospectively assessed the diagnostic ability of dedicated PET $(\mathrm{n}=17)$ or hybrid PET/CT $(\mathrm{n}=23)$ scans with ${ }^{18} \mathrm{~F}^{-} \mathrm{FDG}$ in the evaluation of recurrent and metastatic $\mathrm{BCa}$. In the study, all 35 patients were previously treated for their primary disease. The combined diagnostic information provided by PET/CT affected the clinical management in $17 \%$ of patients. Liu et al. [13] used conventional ${ }^{18} \mathrm{~F}$-FDG PET to detect metastatic disease in 46 patients with $\mathrm{BCa}$. Among patients who had not received previous chemotherapy, the sensitivity was $77 \%$ and the specificity was $97 \%$. However, in 10 patients imaged after receiving chemotherapy, the sensitivity fell to $50 \%$ for detection of histologically confirmed residual/recurrent tumor by ${ }^{18} \mathrm{~F}$-FDG PET.

In a recent systemic review and meta-analysis by $\mathrm{Lu}$ et al. [17] articles published in the period January 2000 and December 2010 were reviewed. Six studies met the inclusion criteria $[4,5,11,14,16,18]$. The pooled sensitivity and specificity of ${ }^{18} \mathrm{~F}-\mathrm{FDG}$ PET or PET/CT for staging or restaging (metastatic lesions) of BCa were 0.82 (95\% CI: 0.72-0.89) and 0.89 (95\% CI: 0.81-0.95), respectively. The authors conclude, that
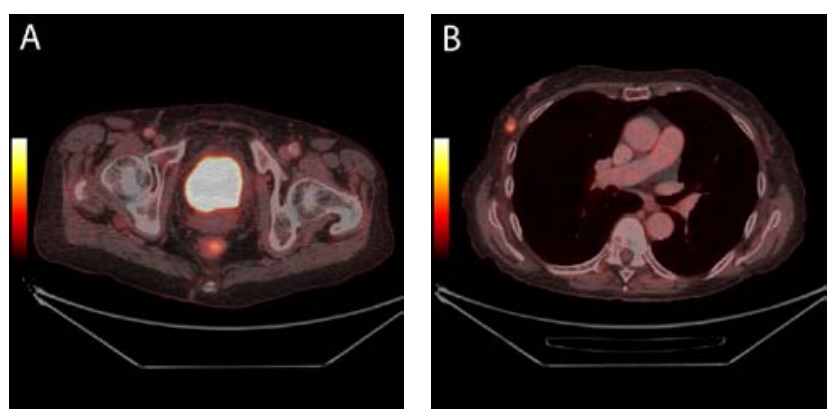

Figure 1: Muscle invasive bladder cancer in a 78-year-old patient. The bladder tumour is not visible on axial ${ }^{18} \mathrm{~F}-\mathrm{FDG} \mathrm{PET} / \mathrm{CT}$ images due to urinary excretion of ${ }^{18} \mathrm{~F}-\mathrm{FDG}$ which mask the tumour $(1 \mathrm{~A})$. No metastases from the bladder tumour were demonstrated. However, a mass suspicious for malignancy was demonstrated in the right breast as can be seen on axial fused PET/CT images (1B). Histology confirmed a primary breast cancer. 


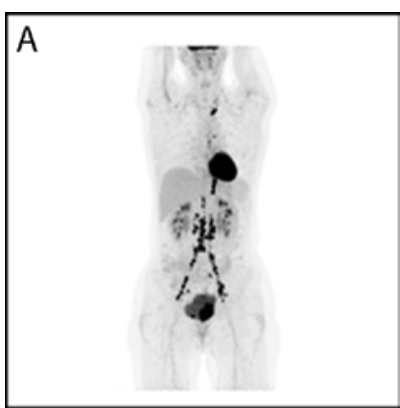

B
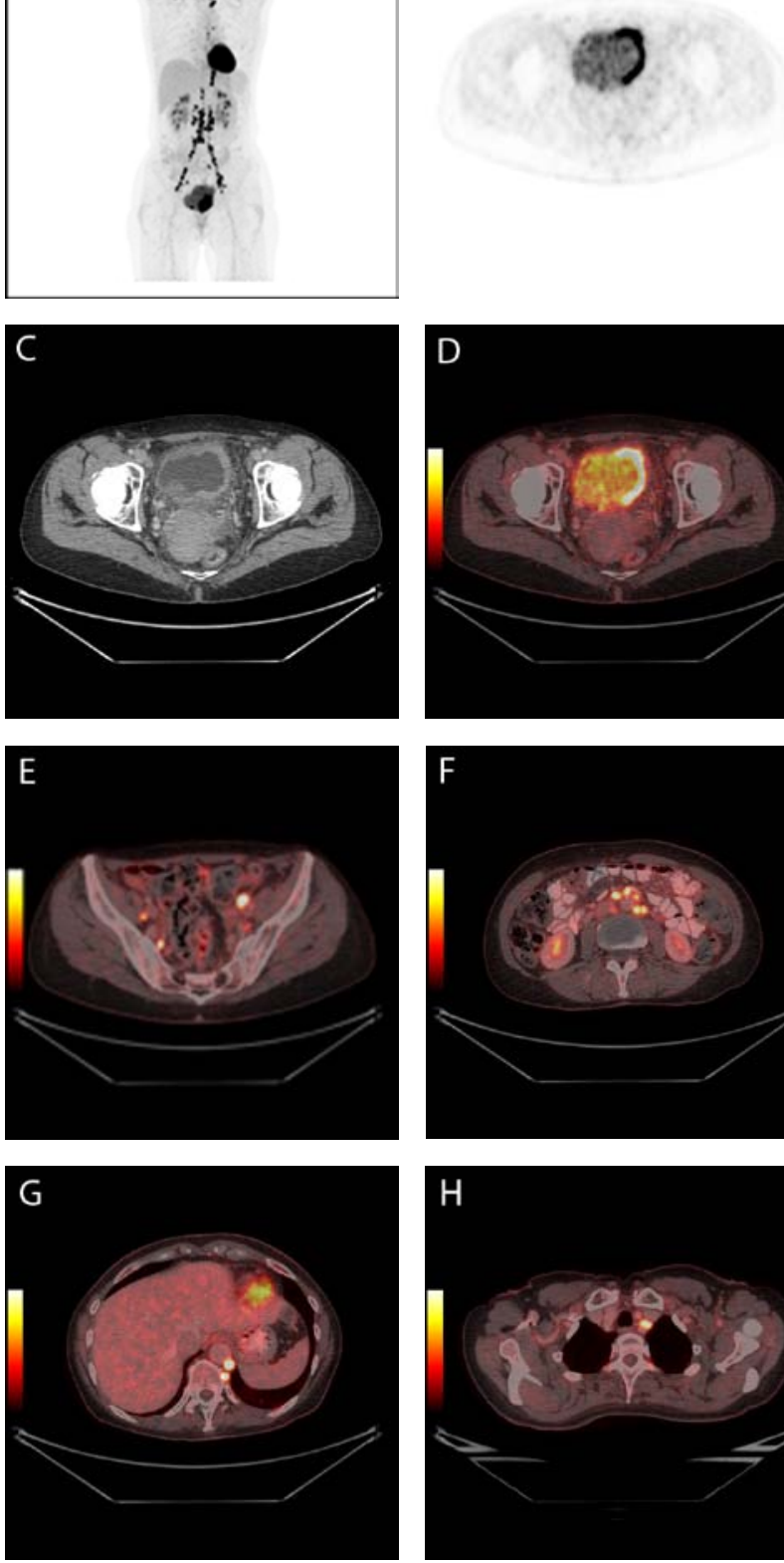
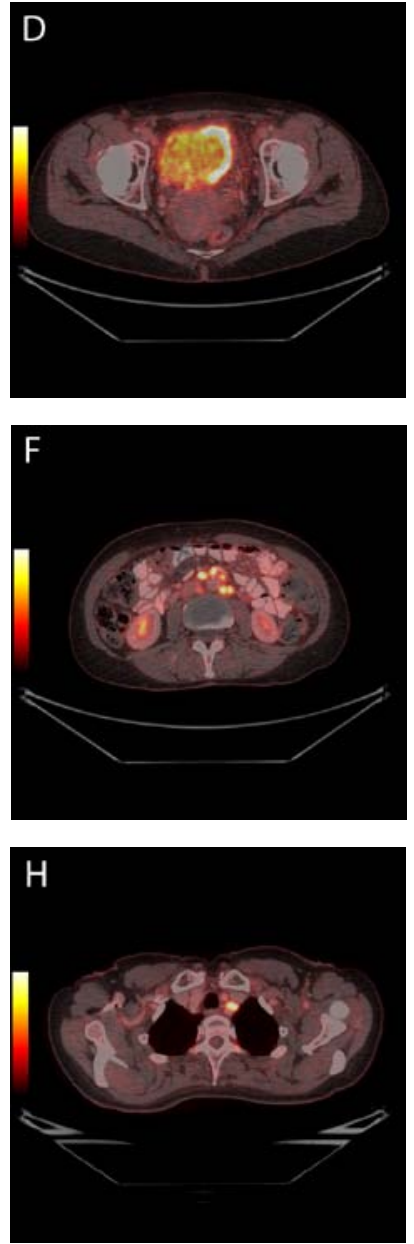

Figure 2: A 56-year-old patient with newly diagnosed muscle invasive bladder cancer underwent ${ }^{18} \mathrm{~F}-\mathrm{FDG}$ PET/CT for staging. The PET image shows the tumour in the bladder as well as multiple lymph node metastases (2A). The tumour can be seen in the left side of the urinary bladder on axial PET image (2B), CT image (2C), and fused PET/CT image (2D). Multiple metastases are seen in lymph nodes located in both sides of the pelvic area $(2 \mathrm{E})$, in retropetoneal lymph nodes $(2 \mathrm{~F})$, in retrocrural lymph nodes and in one lymph node on the left side of trachea $(2 \mathrm{G})$

the results from this meta-analysis suggest that the diagnostic accuracy of ${ }^{18} \mathrm{~F}$-FDG PET or PET/CT is sufficient to warrant its use in staging or restaging (metastatic lesions) of urinary $\mathrm{BCa}$. However due to the small number of patients and limited number of studies analyzed, the diagnostic capability of ${ }^{18} \mathrm{~F}-\mathrm{FDG}$ PET or PET/CT in detection of primary bladder cancer wall lesions could not be assessed. Figure 3 illustrates ${ }^{18} \mathrm{~F}-\mathrm{FDG}$ PET/CT in advanced bladder cancer. Due to urinary excretion of ${ }^{18} \mathrm{~F}-\mathrm{FDG}$ it is difficult to evaluate lesions in the bladder and involvement of the detrusor muscle. Therefore, ${ }^{18} \mathrm{~F}-\mathrm{FDG}$ PET/CT may not play an important role in diagnosing and T-staging of bladder cancer in the future. However, ${ }^{18} \mathrm{~F}-\mathrm{FDG}$ PET/CT may be used for staging and restaging of metastatic disease. Table 1 summarizes PET studies included in this review.

\section{Choline}

To overcome the problem of urinary excretion of ${ }^{18} \mathrm{~F}-\mathrm{FDG}$ ${ }^{11} \mathrm{C}$-choline, which is minimally excreted in urine, has been studied as an alternative tracer for PET/CT imaging in BCa patients. While ${ }^{18} \mathrm{~F}$-labelled choline is excreted in the urine and exhibits activity in the urinary tract comparable to ${ }^{18} \mathrm{~F}-\mathrm{FDG},{ }^{11} \mathrm{C}$-choline is minimally excreted in the urine [19]. ${ }^{11} \mathrm{C}$-choline is incorporated into tumor cells by conversion into ${ }^{11} \mathrm{C}$-phosphorlycholine, which is trapped inside the cell $[19,3]$. This is followed by synthesis of phosphatidylcholine, a main component of cell membranes. The uptake of choline in tumors represents the rate of tumor cell proliferation. The principal disadvantage of ${ }^{11} \mathrm{C}$-choline over ${ }^{18} \mathrm{~F}$-choline is the short half-life of ${ }^{11} \mathrm{C}$ (20 min), which limits its use to centers with on-site cyclotrons. Only few studies have evaluated the role of ${ }^{11} \mathrm{C}$-choline PET/CT in the pre-operative staging of patients before cystectomy [20-23]. Recently, Maurer et al. [21] used diagnostic ${ }^{11} \mathrm{C}$-choline PET/CT for staging 44 patients with $\mathrm{BCa}$ before radical cystectomy and regional lymph node dissection. Histopathologic findings of resected lymph nodes were correlated with the results of PET/CT and CT alone in a patient and field based manner. Lymph node metastases were found in 12 of 44 patients (27\%). On patient-based analysis, sensitivity, specificity, PPV, NPV, and accuracy for ${ }^{11} \mathrm{C}$-choline PET/CT were calculated as $58 \%, 66 \%, 39 \%, 81 \%$, and $64 \%$, respectively; and for CT the calculated percentages were $75 \%, 56 \%, 39 \%, 86 \%$, and $61 \%$, respectively. Twentyfive of 471 dissected lymph node fields (5\%) showed metastases. On field-based analysis, sensitivity, specificity, PPV, NPV, and accuracy for ${ }^{11} \mathrm{C}$-choline PET/CT were $28 \%$, 95\%, 21\%, 96\%, and 91\%, respectively; for CT, the calculated percentages were $39 \%, 92 \%, 20 \%, 96 \%$, and $90 \%$, respectively. The reported values in the study by Maurer et al. [21] are lower than the rates described for ${ }^{11} \mathrm{C}$-choline PET or ${ }^{11} \mathrm{C}$-choline $\mathrm{PET} / \mathrm{CT}$ in previous studies [22-24]. The mean values of sensitivity, specificity, PPV, NPV, accuracy found in these 4 studies are $67 \%, 98 \%$, $94 \%, 91 \%, 90 \%$, respectively [21]. The observed difference in sensitivity and specificity rates might partly be explained by the greater patient number in the prospective study by Maurer et al. [21].

Recently, Golan et al. [20] compared ${ }^{18} \mathrm{~F}-\mathrm{FDG}$ and ${ }^{11} \mathrm{C}$-choline in 20 patients with $\mathrm{BCa}$. A total of 51 lesions showed abnormal tracer activity. The positive predictive value for all detected lesions was $84.7 \%$ for ${ }^{11} \mathrm{C}$-choline PET/CT and $90.7 \%$ for ${ }^{18} \mathrm{~F}-\mathrm{FDG}$ PET/CT. The corresponding PPV for extravesical lesions were $79.4 \%$ and $88.2 \%$, respectively. The authors concluded that within the limitations of a relatively small number of patients and partial histopathological analysis, ${ }^{11} \mathrm{C}$-choline PET/CT appears to have no advantage compared to ${ }^{18} \mathrm{~F}-\mathrm{FDG}$ PET/CT in the detection of metastatic BCa.

\section{Methionine and acetate}

Few studies have used ${ }^{11} \mathrm{C}$-methionine or ${ }^{11} \mathrm{C}$-acetate in $\mathrm{BCa}$ ${ }^{11} \mathrm{C}$-methionine uptake is proportional to the amino acid transport and to some extent protein synthesis [19]. In cancer methionine has been correlated with the amount of viable tumor tissue. Acetate uptake in tumor cells is proportional to lipid synthesis [19]. Ahlstrom et al. [8] found that ${ }^{11} \mathrm{C}$-methionine is superior to ${ }^{18} \mathrm{~F}-\mathrm{FDG}$. With ${ }^{11} \mathrm{C}$-methionine $\mathrm{PET}$ it was possible to detect $18 / 23$ primary tumours. 

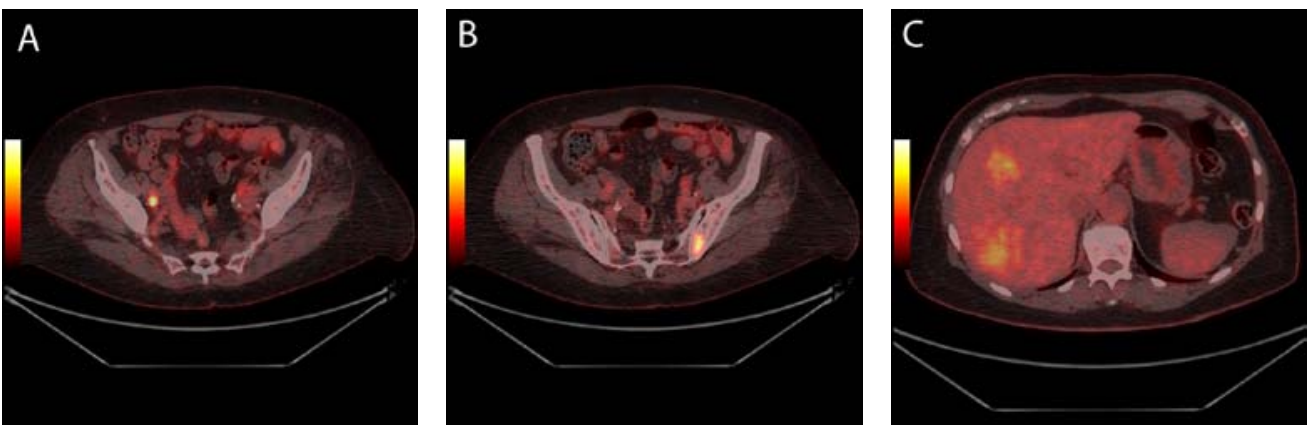

Figure 3: Muscle invasive bladder cancer in a 73-year-old patient. The tumour could not be seen in the urinary bladder on ${ }^{18} \mathrm{~F}-\mathrm{FDG}$ PET/CT. However, metastases were demonstrated in one lymph node in the right side of the pelvis $(3 A)$, in the bone (3B), and (3C) in the liver.

\begin{tabular}{|c|c|c|c|c|c|}
\hline Authors & Year & Tracer & Sensitivity/specificity & PPV/NPV & Number of patients enrolled \\
\hline Ahlstrom et al. [8] & 1996 & ${ }^{18} \mathrm{~F}-\mathrm{FDG}$ & 0.78 (sensitivity) & NA & 23 \\
\hline Kosuda et al. [7] & 1997 & ${ }^{18} \mathrm{~F}-\mathrm{FDG}$ & 0.67 (sensitivity) & NA & 12 \\
\hline Bachor et al. [9] & 1999 & ${ }^{18} \mathrm{~F}-\mathrm{FDG}$ & $0.67 / 0.86$ & NA & 64 \\
\hline Drieskens et al. [11] & 2005 & ${ }^{18} \mathrm{~F}-\mathrm{FDG}$ & $0.60 / 0.88$ & NA & 55 \\
\hline Liu et al. [13] & 2006 & ${ }^{18} \mathrm{~F}-\mathrm{FDG}$ & $0.77 / 0.97$ & NA & 46 \\
\hline Anjos et al. [4] & 2007 & ${ }^{18} \mathrm{~F}-\mathrm{FDG}$ & 0.54 (sensitivity) & NA & 11 \\
\hline Jadvar et al. [16] & 2008 & ${ }^{18} \mathrm{~F}-\mathrm{FDG}$ & $1 / 0.54$ & NA & 35 \\
\hline Kibel et al. [14] & 2009 & ${ }^{18} \mathrm{~F}-\mathrm{FDG}$ & $0.70 / 0.94$ & $0.78 / 0.91$ & 43 \\
\hline Apolo et al. [15] & 2010 & ${ }^{18} \mathrm{~F}-\mathrm{FDG}$ & $0.87 / 0.88$ & NA & 47 \\
\hline Harkirat et al. [5] & 2010 & ${ }^{18} \mathrm{~F}-\mathrm{FDG}$ & $0.87 / 1$ & $1 / 0.78$ & 22 \\
\hline Lodde et al. [6] & 2010 & ${ }^{18} \mathrm{~F}-\mathrm{FDG}$ & $\begin{array}{l}0.85 / 0.25 \text { (bladder) } \\
0.75 / 1 \text { (LN based) }\end{array}$ & NA & 44 \\
\hline Swinnen et. al. [12] & 2010 & ${ }^{18} \mathrm{~F}-\mathrm{FDG}$ & $0.46 / 0.97$ & NA & 51 \\
\hline Jensen et al. [10] & 2011 & ${ }^{18} \mathrm{~F}-\mathrm{FDG}$ & $0.33 / 0.93$ & $0.50 / 0.88$ & 18 \\
\hline Golan et al. [20] & 2011 & $\begin{array}{l}{ }^{18} \mathrm{~F}-\mathrm{FDG} \\
{ }^{11} \mathrm{C} \text {-choline }\end{array}$ & & $\begin{array}{l}{ }^{18} \mathrm{~F}-\mathrm{FDG}: \\
0.91 \text { (PPV, bladder) } \\
0.88 \text { (PPV, MET) } \\
{ }^{11} \mathrm{C} \text {-choline: } \\
0.85 \text { (PPV, bladder) } \\
0.79 \text { (PPV, MET) }\end{array}$ & 20 \\
\hline Ahlstrom et al. [8] & 1996 & $\begin{array}{l}{ }^{18} \mathrm{~F}-\mathrm{FDG} \\
{ }^{11} \mathrm{C}-\text {-methionine }\end{array}$ & $\begin{array}{l}0.78 \text { (sensitivity, } \\
{ }^{11} \mathrm{C} \text {-methionine) }\end{array}$ & NA & 23 (only 2 with also ${ }^{18} \mathrm{~F}-\mathrm{FDG}$ ) \\
\hline De Jong et al. [24] & 2002 & ${ }^{11} \mathrm{C}$-choline & 0.91 (sensitivity) & NA & 11 \\
\hline Gofrit et al. [23] & 2006 & ${ }^{11} \mathrm{C}$-choline & 1 (sensitivity) & NA & 18 \\
\hline Picchio et al. [22] & 2006 & ${ }^{11} \mathrm{C}$-choline & $\begin{array}{l}0.96 \text { (sensitvity, bladder) } \\
0.62 \text { (sensitivity, LN) }\end{array}$ & NA & 27 \\
\hline Maurer et al. [21] & 2012 & ${ }^{11} \mathrm{C}$-choline & $0.58 / 0.66$ & $0.39 / 0.81$ & 44 \\
\hline Letocha et al. [25] & 1994 & ${ }^{11} \mathrm{C}$-methionine & NA & NA & 44 \\
\hline Schoder et al. [26] & 2012 & ${ }^{11} \mathrm{C}$-acetate & $1 / 0.88$ & NA & 17 \\
\hline
\end{tabular}

Table 1: PET/CT studies included in the review.

Letocha et al. [25] investigated whether ${ }^{11} \mathrm{C}$-methionine could be used for the evaluation of therapy response in 44 patients with varying stages of $\mathrm{BCa}$ treated with chemotherapy. In the study, the diagnostic accuracy of PET was poor and the technique could not monitor the therapeutic effect of neoadjuvant chemotherapy, producing results that correlated with therapy outcome. In a recent pilot study performed at MSKCC, Schoder et al. [26] investigated the utility of ${ }^{11} \mathrm{C}$-acetate PET/ $\mathrm{CT}$ for staging of $\mathrm{BCa}$, and response assessment after neoadjuvant chemotherapy. Seventeen patients underwent ${ }^{11} \mathrm{C}$-acetate PET/CT before radical cystectomy and pelvic lymph node dissection. Ten patients had undergone neo adjuvant chemotherapy prior to PET. Eight of 10 residual tumours showed abnormal ${ }^{11} \mathrm{C}$-acetate uptake; two cases of residual TiS were false negative, three cases were false positive, and three true negative. The authors concluded that ${ }^{11} \mathrm{C}$-acetate has good sensitivity for bladder cancer and lymph node metastases.
However, false positive uptake due to inflammation or granulomatous infection can occur, limiting the staging utility of ${ }^{11} \mathrm{C}$-acetate after prior intravesical BCG therapy. The role of both ${ }^{11} \mathrm{C}$-methionine and ${ }^{11} \mathrm{C}$-acetate in bladder cancer remains to be elucidated further in larger prospective trials.

\section{MRI}

Magnetic Resonance Imaging (MRI) currently is the most promising non-invasive imaging modality for the localization and assessment of $\mathrm{BCa}$ tumour extension and adjacent organ involvement of $\mathrm{BCa}$ due to its superior spatial and contrast resolution. Beside its multi-planar anatomical imaging utility, MRI has the potential to offer functional information through pulse sequences such as Diffusion Weighted MRI (DW MRI) and Dynamic Contrast Enhanced MRI (DCE MRI). One major clinical challenge in managing BCa patients is 
accurate depiction of the tumor with regard to its depth of penetration into the bladder wall. Patients with No Muscle Invasion (NMI) have much better prognosis than patients with Muscle Invasion (MI) and treatment (bladder sparing surgery vs. radical surgery) vary accordingly [27]. Although anatomical MRI based on T1 and T2 weighted MRI has been reported to be useful to some extent for local staging of BCa it has several well known limitations and the added utility of functional MRI for tumor staging has yet to be definitively determined.

A dedicated bladder MRI protocol should include anatomical T2 weighted (T2W) MRI in three planes (axial, sagittal and coronal) and functional pulse sequences (DW MRI, DCE MRI). Moreover, a large field of view axial T1W fat saturated spin echo can be helpful to evaluate lymph nodes and bones. A surface coil is used to increase Signal To Noise Ratios (SNR). The bladder should be comfortably full since the tumor may be hidden if the bladder is completely emptied or effaced if it is too distended which can also trigger unwanted contractions resulting in decreased accuracy of the scans and patient discomfort. Therefore, a moderately full bladder is preferred during image acquisition. Use of a bowel antiperistaltic (e.g. IM Glucagon') is sometimes advised where the intestinal loops lie close to the bladder wall, creating artifacts.

On T2W MRI, the posterior muscular layer of the bladder (also known as the detrussor muscle) appears as a hypointense line. $\mathrm{BCa}$ lesions, which can be superficial or papillary, appear as hypo to isointense filling defects compared to the urine (Figure 4). In NMI lesions there is no interruption of the detrussor muscle layer by the tumor; however in the case of MI the low signal intensity of the detrussor muscle is interrupted by the tumor. T2W MRI has the capability of demonstrating the perivesical spread, which is seen as a direct projection of the lesion into the perivesicle fat tissue; moreover invasion of neighbouring organs, such as prostate, seminal vesicles, uterus, vagina, pelvic and abdominal wall can be readily seen on T2W MRI. Intra-luminal clot and/or stones can sometimes lead to false positive diagnosis on T2W MRI, however utilization of functional modalities such as contrast enhanced MRI and DW MRI can avoid this since their signal pattern are quite different from that of tumors.

Optical cystoscopy of the bladder is a time honored diagnostic method that provides high resolution scanning of the bladder mucosa. MR Cystoscopy (MRC) can be a useful adjunct to conventional cystoscopy to localize difficult-to-see lesions for instance, those that require retroflexing of the scope. There are two basic methods for performing MRC: 1-Acquiring 3D T1W MRI after opacification of the lumen with gadolinium administered either retrograde by catheter or intravenously, 2-Acquiring 3D T2W MRI after luminal distention with urine without any specific preparation. The 3D data sets obtained from both methods can be evaluated by multi-planar, 3D or virtual cystoscopic "fly-through" reconstruction methods [28]. There are a limited number of publications about the utility of MRC for BCa detection and staging. Lammle et al. [29] reported detection rates of $90.9 \%$ and $100 \%$ for all tumors and for tumors greater than $1 \mathrm{~cm}$, respectively in $24 \mathrm{BCa}$ patients. Beer et al. [30] reported sensitivity and specificity of $91 \%$ for MRC in 32 patients with 43 lesions. MRC has several advantages over conventional cystoscopy such as being relatively impervious to hematuria, urethral strictures and anterior bladder wall lesions (which can be difficult to reach via cystoscopy), however, its limitations include a time consuming costly procedure requiring expertise which has difficulty detecting of flat lesions. Importantly, it is not possible to perform a biopsy with MRC (Figure 5).

Functional MRI sequences for BCa include DW MRI and DCE MRI. DW-MRI is an intrinsically low resolution pulse sequence which
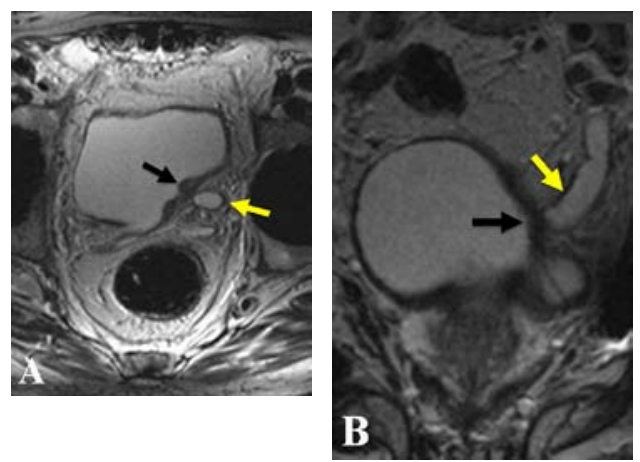

Figure 4: 56-year-old patient with hematuria. Axial (A) and coronal (B) T2W MR images demonstrate a hypointense superficial bladder cancer lesion (black arrows in A and B), which leads to obstruction of the left ureter (yellow arrows in A and B). (Courtesy of Dr. Omer Aras from University of Maryland, Baltimore MD,USA).
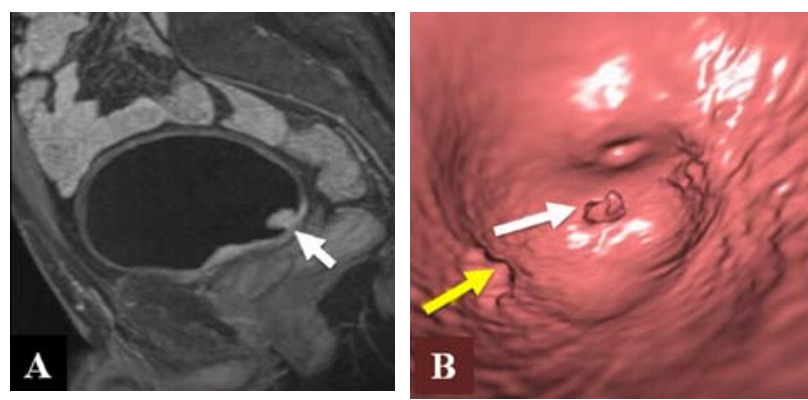

Figure 5: 62-year-old patient with hematuria. Sagittal contrast enhanced T1W MR image (A) demonstrated an enhancing papillary lesion consistent with bladder cancer (white arrow), virtual MR cystoscopy MR image (B) confirms the presence of a papillary bladder cancer lesion (white arrow), near the orifice of the left ureter (yellow arrow) (B). (Courtesy of Dr. Evrim B. Turkbey from Radiology and Imaging Sciences Department, Clinical Center $\mathrm{NIH}$, Bethesda, MD, USA).
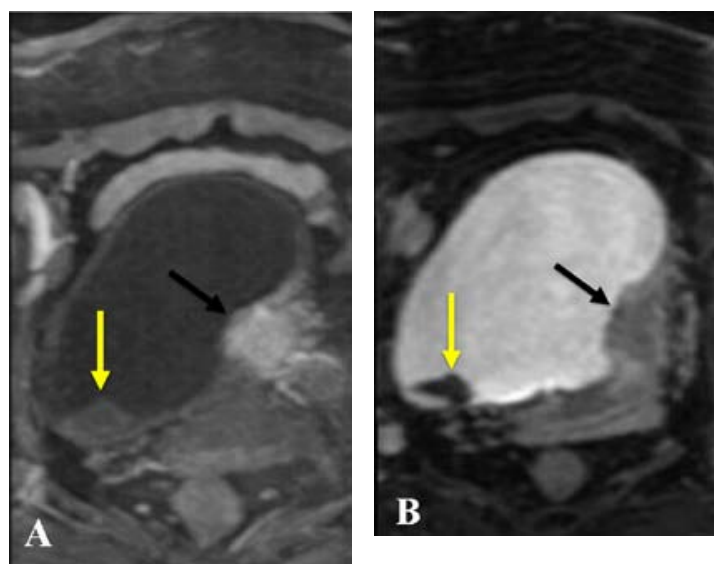

Figure 6: 58-year-old patient with hematuria. Axial arterial phase contrast enhanced T1W MR image demonstrates a left sided enhancing lesion (black arrow) and a right sided unenhancing lesion (yellow arrow) (A); delayed phase contrast enhanced T1W MR image shows persistent enhancement of the left sided lesion (black arrow) consistent with bladder cancer; whereas the right sided lesion doesn't not enhance which is consistent with blood clot (yellow arrow) (B). (Courtesy of Dr. Evrim B. Turkbey from Radiology and Imaging Sciences Department, Clinical Center NIH, Bethesda, MD, USA). 
evaluates the Brownian motion of free water molecules within tissues. Apparent Diffusion Coefficient (ADC) values derived from DW MRI allow this technique to be quantifiable and reproducible. BCa lesions most commonly appear hyperintense on DW MRI, whereas they demonstrate reduced ADC values compared to the detrussor muscle layer due to their increased cellularity. The added value of DW MRI compared to anatomical T2W MRI has recently been evaluated. Matsuki et al. [31] reported the sensitivity and Positive Predictive Value (PPV) of DW-MRI to be $100 \%$ in 15 patients with 17 cystoscopy proven BCa lesions. Watanabe et al. [32] evaluated performance of DW MRI in tumor staging of $\mathrm{BCa}$ in 18 patients and reported sensitivity, specificity, accuracy, area under the curve $80 \%, 79 \%, 70 \%, 0.77$, respectively Abou-El-Ghar et al. [33] compared T2W MRI and DW MRI in the detection of $\mathrm{BCa}$ in 130 patients and reported sensitivity/ specificity values of $96 \% / 86 \%$ and $98 \% / 92 \%$ for T2W MRI and DW MRI, respectively; however they didn't report their results for tumor staging. Takeuchi et al. [34] evaluated the ability of DW MRI to stage $\mathrm{BCa}$ and correlated $\mathrm{ADC}$ values with histological grade in 40 patients. The reported accuracy of T2W MRI and combined T2W MRI-DW MRI were $88 \%$ and $88 \%$, respectively. Additionally, they concluded that the ADC value of Grade 3 tumors was significantly lower than that of Grade 1 and Grade 2 tumors. El-Assmy et al. [35] evaluated DW MRI and T2W MRI for tumor staging in 206 BCa patients and reported a staging accuracy of $63.6 \%$ and $39.6 \%$ for DW MRI and T2W MRI, respectively. Avcu et al. [36] investigated the role of DW MRI in the diagnosis of $\mathrm{BCa}$ in 63 patients and reported a sensitivity, specificity and accuracy of $100 \%, 76.5 \%$ and $93.7 \%$, respectively; however this study didn't report the accuracy for tumor staging. Kobayashi et al. [37] studied the performance of DW MRI and T2W MRI for BCa staging in 104 patients. T2W MRI and DW MRI were found to have almost equivalent sensitivity for tumor detection (91\%); whereas a cut off ADC value of $0.86 \times 10^{-3} \mathrm{~mm}^{2} / \mathrm{sec}$ was found to best differentiate clinically aggressive disease from less aggressive disease with a sensitivity, specificity and accuracy of $88 \%, 85 \%$ and $87 \%$, respectively. Despite these promising initial results, the utilization of DW MRI in $\mathrm{BCa}$ detection and local staging is confined to the research setting.

DCE MRI provides an index of the vascularity of the tumor compared to normal bladder wall. In DCE MRI, Fast Gradient Recalled Echo (GRE) T1W images are obtained before, during and after the intravenous injection of gadolinium chelate contrast agents. On DCE MRI, normal bladder wall enhances very slightly, but BCa lesions tend to enhance earlier and more intensely than the remainder of the bladder wall (Figure 6). Scattoni et al. [38] evaluated 48 BCa patients for tumor staging via T2W MRI and DCE MRI. T2W MRI and DCE MRI correctly classified superficial involvement of the bladder wall in $68 \%$ and $84 \%$, respectively; whereas the overall accuracy for tumor staging was $71 \%$ and $81 \%$, respectively. Barentsz et al. [39] studied 61 BCa patients and reported an accuracy of $84 \%$ for tumor staging via DCE MRI, moreover, they were able to demonstrate that $\mathrm{BCa}$ lesions start to enhance as early as 6.5 seconds (+/- 3.5 seconds) after contrast injection whereas normal bladder wall enhances later. Tekes et al. [40] evaluated $71 \mathrm{BCa}$ patients with T2W MRI, precontrast T1W MRI and DCE MRI and reported an accuracy of $62 \%$ on a stage-by-stage basis, moreover, there improved to $85 \%$ and $82 \%$ in differentiating superficial from invasive tumors and organ confined from non-organ confined tumors, respectively. Tuncbilek et al. [41] investigated the correlation of semi-quantitative DCE MRI parameters (peak time enhancements in the $1^{\text {st }}$ to $5^{\text {th }}$ minutes and the steepest slope) with microvessel density, histologic grade, in 24 patients. They demonstrated a significant if modest correlation between DCE MRI parameters and microvessel density $(r=0.483)$, and histologic grade $(r=0.47)$.

Nodal staging of BCa with MRI is limited since it currently depends strictly on the size of the nodes. Large nodes can simply be hyperplastic and malignant nodes are not always enlarged leading to false positive and false negative results when size alone is used as the criterion for positivity for nodes. Ultrasmall Superparamagnetic IronOxide (USPIO) (Ferumoxtran-10) enhanced MRI has been reported to improve lymph node staging in several studies, however this agent is no longer available for human use. Deserno et al. [42] studied $58 \mathrm{BCa}$ patients and reported a sensitivity and negative predictive value of $96 \%$ and $98 \%$ for ferumoxtran-10 enhanced MRI. Thoeny et al.[43] assessed $21 \mathrm{BCa}$ and/or prostate cancer patients with USPIO enhanced MRI and DW MRI. They reported a diagnostic accuracy of $90 \%$ for detecting metastatic lymph nodes. In the absence of the availability of this agent, researchers are investigating whether ferumoxytol, a similar compound which is approved for use as an iron replacement therapy in patients with chronic renal disease, might substitute for ferumoxtran-10. Table 2 summarizes MRI studies included in this review.

\section{Conclusion}

Imaging plays a mainstay role in the evaluation of $\mathrm{BCa}$, especially for diagnosis, local and distant staging and treatment follow up. ${ }^{18} \mathrm{~F}-\mathrm{FDG}$ PET/CT is useful for detection of metastatic disease, but the ability to detect primary bladder wall lesions remains to be elucidated further. To overcome the problem with urinary excretion of ${ }^{18} \mathrm{~F}-\mathrm{FDG}$, new PET tracers are being tested. MRI is a feasible and accurate technique for the local staging of $\mathrm{BCa}$. Anatomical MRI has a modest utility is tumour NM-staging of BCa. However, incorporation of functional techniques, such as DW MRI can improve the results for lesion detection and staging and multi-parametric MRI's role is yet to be explored widely.

\begin{tabular}{|l|l|l|l|l|l|}
\hline Authors & Year & MRI Sequence(s) & Sensitivity/specificity & PPV/NPV \\
\hline Scattoni et al. [38] & 1996 & DCE MRI & NA & $0.56-0.84$ (PPV) \\
\hline Barentsz et al. [39] & 1996 & DCE MRI & $0.9 / 0.33-0.92$ & $0.87-0.98 / 0.44-0.69$ & 61 \\
\hline Lammle et al. [29] & 2002 & MR cystoscopy & NA & 0.91 (PPV) & NA \\
\hline Beer et al. [30] & 2004 & MR cystoscopy & $0.91 / 0.91$ & $0.71-0.77 / 0.55-0.96$ \\
\hline Tekes et al. [40] & 2005 & T2W MRI, DCE MRI & $0.79-0.97 / 0.55-0.84$ & 1 (PPV) \\
\hline Matsuki et al. [31] & 2007 & DW MRI & $1($ sensitivity) & NA & 1 \\
\hline Watanabe et al. [32] & 2009 & DW MRI & $0.8 / 0.79$ & $1 / 0.92$ \\
\hline Abou El-Ghar et al. [33] & 2009 & DW MRI & $0.98 / 0.92$ & NA \\
\hline Takeuchi et al. [34] & 2009 & DW MRI & $0.80 / 0.94$ & 1 (PPV) \\
\hline El-Assmy et al. [35] & 2009 & DW MRI & $0.96-0.98$ (sensitivity) & NA \\
\hline Avcu et al. [36] & 2011 & DW MRI & $1 / 0.76$ & NA \\
\hline Kobayashi et al. [37] & 2011 & DW MRI & $0.92 / 0.80-90$ & 19 \\
\hline
\end{tabular}

Table 2: MRI studies included in the review. 


\section{Acknowledgment} 010655.

This article was funded by National Institutes of Health (NIH Grant ZIA BC

\section{References}

1. Kaufman DS, Shipley WU, Feldman AS (2009) Bladder cancer. Lancet 374: 239-249

2. Stein JP, Lieskovsky G, Cote R, Groshen S, Feng AC, et al. (2001) Radical cystectomy in the treatment of invasive bladder cancer: long-term results in 1,054 patients. J Clin Oncol 19: 666-675.

3. Bouchelouche K, Oehr P (2008) Positron emission tomography and positron emission tomography/computerized tomography of urological malignancies: an update review. J Urol 179: 34-45.

4. Anjos DA, Etchebehere EC, Ramos CD, Santos AO, Albertotti C, et al. (2007) 18F-FDG PET/CT delayed images after diuretic for restaging invasive bladder cancer. J Nucl Med 48: 764-770.

5. Harkirat S, Anand S, Jacob M (2010) Forced diuresis and dual-phase F-fluorodeoxyglucose-PET/CT scan for restaging of urinary bladder cancers. Indian J Radiol Imaging 20: 13-19.

6. Lodde M, Lacombe L, Friede J, Morin F, Saourine A, et al. (2010) Evaluation of fluorodeoxyglucose positron-emission tomography with computed tomography for staging of urothelial carcinoma. BJU Int 106: 658-663.

7. Kosuda S, Kison PV, Greenough R, Grossman HB, Wahl R (1997) Preliminary assessment of fluorine-18 fluorodeoxyglucose positron emission tomography in patients with bladder cancer. Eur J Nucl Med 24: 615-620.

8. Ahlström $\mathrm{H}$, Malmström $\mathrm{PU}$, Letocha $\mathrm{H}$, Andersson J, Långström $\mathrm{B}$, et al (1996) Positron emission tomography in the diagnosis and staging of urinary bladder cancer. Acta Radiol 37: 180-185.

9. Bachor R, Kotzerke J, Reske SN, Hautmann R (1999) Lymph node staging of bladder neck carcinoma with positron emission tomography. Urologe A 38 : 46-50

10. Jensen TK, Holt P, Gerke O, Riehmann M, Svolgaard B, et al. (2011) Preoperative lymph-node staging of invasive urothelial bladder cancer with 18F-fluorodeoxyglucose positron emission tomography/computed axial tomography and magnetic resonance imaging: correlation with histopathology. Scand J Urol Nephrol 45: 122-128.

11. Drieskens O, Oyen R, Van Poppel H, Vankan Y, Flamen P, et al. (2005) FDGPET for preoperative staging of bladder cancer. Eur J Nucl Med Mol Imaging 32: $1412-1417$

12. Swinnen G, Maes A, Pottel H, Vanneste A, Billiet I, et al. (2010) FDG-PET/CT for the preoperative lymph node staging of invasive bladder cancer. Eur Uro 57: 641-647

13. Liu IJ, Lai YH, Espiritu JI, Segall GM, Srinivas S, et al. (2006) Evaluation of fluorodeoxyglucose positron emission tomography imaging in metastatic transitional cell carcinoma with and without prior chemotherapy. Urol Int 77 : 69-75

14. Kibel AS, Dehdashti F, Katz MD, Klim AP, Grubb RL, et al. (2009) Prospective study of [18F]fluorodeoxyglucose positron emission tomography/computed tomography for staging of muscle-invasive bladder carcinoma. J Clin Oncol 27: 4314-4320.

15. Apolo AB, Riches J, Schöder H, Akin O, Trout A, et al. (2010) Clinical value of fluorine-18 2-fluoro-2-deoxy-D-glucose positron emission tomography/ computed tomography in bladder cancer. J Clin Oncol 28: 3973-3978.

16. Jadvar H, Quan V, Henderson RW, Conti PS (2008) [F-18]-Fluorodeoxyglucose PET and PET-CT in diagnostic imaging evaluation of locally recurrent and metastatic bladder transitional cell carcinoma. Int J Clin Oncol 13: 42-47.

17. Lu YY, Chen JH, Liang JA, Wang HY, Lin CC, et al. (2011) Clinical value of FDG PET or PET/CT in urinary bladder cancer: A systemic review and metaanalysis. Eur J Radiol.

18. Apolo AB, Pandit-Taskar N, Morris MJ (2008) Novel tracers and their development for the imaging of metastatic prostate cancer. J Nucl Med 49: 2031-2041.

19. Jana S, Blaufox MD (2006) Nuclear medicine studies of the prostate, testes, and bladder. Semin Nucl Med 36: 51-72.
20. Golan S, Sopov V, Baniel J, Groshar D (2011) Comparison of 11C-choline with 18F-FDG in positron emission tomography/computerized tomography for staging urothelial carcinoma: a prospective study. J Urol 186: 436-441.

21. Maurer T, Souvatzoglou M, Kübler H, Opercan K, Schmidt S, et al. (2012) Diagnostic efficacy of [11C]choline positron emission tomography/computed tomography compared with conventional computed tomography in lymph node staging of patients with bladder cancer prior to radical cystectomy. Eur Urol 61 : 1031-1038.

22. Picchio M, Treiber U, Beer AJ, Metz S, Bössner P, et al. (2006) Value of 11C-choline PET and contrast-enhanced CT for staging of bladder cancer: correlation with histopathologic findings. J Nucl Med 47: 938-944.

23. Gofrit ON, Mishani E, Orevi M, Klein M, Freedman N, et al. (2006) Contribution of $11 \mathrm{C}$-choline positron emission tomography/computerized tomography to preoperative staging of advanced transitional cell carcinoma. J Urol 176: 940 944

24. de Jong IJ, Pruim J, Elsinga PH, Jongen MM, Mensink HJ, et al. (2002) Visualisation of bladder cancer using (11)C-choline PET: first clinica experience. Eur J Nucl Med Mol Imaging 29: 1283-1288.

25. Letocha $\mathrm{H}$, Ahlstrom $\mathrm{H}$, Malmstrom PU, Westlin JE, Fasth KJ, et al. (1994) Positron emission tomography with L-methyl-11C-methionine in the monitoring of therapy response in muscle-invasive transitional cell carcinoma of the urinary bladder. Br J Urol 74: 767-774.

26. Schoder H, Ong SC, Reuter VE, Cai S, Burnazi E, et al. (2012) Initial Results with (11)C-Acetate Positron Emission Tomography/Computed Tomography (PET/CT) in the Staging of Urinary Bladder Cancer. Mol Imaging Biol 14: 245 251.

27. Stenzl A, Cowan NC, De Santis M, Kuczyk MA, Merseburger AS, et al. (2011) Treatment of muscle-invasive and metastatic bladder cancer: update of the EAU guidelines. Eur Urol 59: 1009-1018.

28. Beer A, Saar B, Rummeny EJ (2003) Tumors of the urinary bladder: technique current use, and perspectives of MR and CT cystography. Abdom Imaging 28 868-876.

29. Lammle M, Beer A, Settles M, Hannig C, Schwaibold H, et al. (2002) Reliability of MR imaging-based virtual cystoscopy in the diagnosis of cancer of the urinary bladder. AJR Am J Roentgenol 178: 1483-1488.

30. Beer A, Saar B, Zantl N, Link TM, Roggel R, et al. (2004) MR cystography for bladder tumor detection. Eur Radiol 14: 2311-2319.

31. Matsuki M, Inada Y, Tatsugami F, Tanikake M, Narabayashi I, et al. (2007) Diffusion-weighted MR imaging for urinary bladder carcinoma: initial results. Eur Radiol 17: 201-204.

32. Watanabe H, Kanematsu M, Kondo H, Goshima S, Tsuge Y, et al. (2009) Preoperative $T$ staging of urinary bladder cancer: does diffusion-weighted MR have supplementary value? AJR Am J Roentgenol 192: 1361-1366.

33. Abou-El-Ghar ME, El-Assmy A, Refaie HF, El-Diasty T (2009) Bladder cancer diagnosis with diffusion-weighted MR imaging in patients with gross hematuria Radiology 251: 415-421.

34. Takeuchi M, Sasaki S, Ito M, Okada S, Takahashi S, et al. (2009) Urinary bladder cancer: diffusion-weighted MR imaging--accuracy for diagnosing $T$ stage and estimating histologic grade. Radiology 251: 112-121.

35. El-Assmy A, Abou-El-Ghar ME, Mosbah A, El-Nahas AR, Refaie HF, et al. (2009) Bladder tumour staging: comparison of diffusion- and T2-weighted MR imaging. Eur Radiol 19: 1575-1581.

36. Avcu S, Koseoglu MN, Ceylan K, Bulut MD, Unal O (2011) The value of diffusion-weighted $\mathrm{MRI}$ in the diagnosis of malignant and benign urinary bladder lesions. Br J Radiol 84: 875-882.

37. Kobayashi S, Koga F, Yoshida S, Masuda H, Ishii C, et al. (2011) Diagnostic performance of diffusion-weighted magnetic resonance imaging in bladder cancer: potential utility of apparent diffusion coefficient values as a biomarker to predict clinical aggressiveness. Eur Radiol 21: 2178-2186.

38. Scattoni V, Da Pozzo LF, Colombo R, Nava L, Rigatti P, et al. (1996) Dynamic gadolinium-enhanced magnetic resonance imaging in staging of superficial bladder cancer. J Urol 155: 1594-1599.

39. Barentsz JO, Jager GJ, van Vierzen PB, Witjes JA, Strijk SP, et al. (1996) Radiology 201: 185-193. 
Citation: Bouchelouche K, Turkbey B, Choyke PL (2012) PET/CT and MRI in Bladder Cancer. J Cancer Sci Ther S14:001. doi:10.4172/1948-5956. S14-001

40. Tekes A, Kamel I, Imam K, Szarf G, Schoenberg M, et al. (2005) Dynamic MRI of bladder cancer: evaluation of staging accuracy. AJR Am J Roentgenol 184: 121-127.

41. Tuncbilek N, Kaplan M, Altaner S, Atakan IH, Sut N, et al. (2009) Value of dynamic contrast-enhanced MRI and correlation with tumor angiogenesis in bladder cancer. AJR Am J Roentgenol 192: 949-955.

42. Deserno WM, Harisinghani MG, TaupitzM, Jager GJ, Witjes JA, Mulders PF et al. (2004) Urinary bladder cancer: preoperative nodal staging with ferumoxtran10-enhanced MR imaging. Radiology 233: 449-456.

43. Thoeny HC, Triantafyllou M, Birkhaeuser FD, Froehlich JM, Tshering DW et al. (2009) Combined ultrasmall superparamagnetic particles of iron oxideenhanced and diffusion-weighted magnetic resonance imaging reliably detect pelvic lymph node metastases in normal-sized nodes of bladder and prostate cancer patients. Eur Urol 55: 761-769.

This article was originally published in a special issue, Cancer: Molecular Imaging handled by Editor(s). Dr. Zhen Cheng, Stanford University, USA 